\title{
A evolução científica e tecnológica e a ética do médico
}

\author{
Scientific and technological evolution and the physician's ethic
}

\author{
Reinaldo Ayer de 0 liveira*
}

0

progresso em diversas áreas da medicina resultou dos avanços científicos e tecnológicos ocorridos nas últimas décadas. Em pouco tempo, as conquistas e possibilidades de diagnósticos mais precisos e procedimentos terapêuticos avançados chegaram às mãos dos médicos e ao desejo dos doentes portadores de doenças graves. rente ${ }^{1}$.

$\mathrm{N} \mathrm{a}$ angiologia e cirurgia vascular, não foi dife-

O s meios de comunicação e divulgação, como a tel evisão e a internet, estão permitindo que a informação científica atinja rapidamente e ao mesmo tempo os médicos e os doentes. Freqüentemente, os médicos são procurados para opinarem sobre procedimentos queos doentes ficam sabendo pela mídia. Esta novidade na relação médico-paciente, aliadaa certa competitividade entre médicos, tem gerado algumas inquietações no âmbito da ética.

Sem dúvida, a partir da década de 1990, os avanços nas áreas de angiologia e da cirurgia vascular não significaram apenas a introdução de uma nova linguagem de possibilidades, mas, sobretudo, queo aperfeiçoamento científico e técnico despertava uma ousadia de cirurgiões que procuravam soluções inovadoras, com o objetivo de ofertar, aos doentes, possibilidades de cura ou controledesuasdoenças. Estar atual izado erealizando novos procedimentos significa, também, aumento de clientela. $\mathrm{H}$ á, portanto, um movimento legítimo que, de um lado, procura levar para o indivíduo, em particular, aquilo que existe de mais avançado em diagnóstico etratamento na solução do seu problemade saúde, eque, de outro lado, busca o sucesso do médico.

O smovimentos sociais, na década de 1960 , colocaram em evidência a necessidade de uma reflexão ética mais abrangente sobre os procedimentos na área da saúde. U m exemplo marcante de conflito ético aconteceu quando da criação do primeiro centro de hemodiálise nos EUA, nos anos de 1960. Como não havia equipamento suficiente para o tratamento de todos os pacientes com indicação para essa terapia, surgiu um grande problema para definir critérios de prioridades. N esta ocasião, foram constituídos os primeiros comitês deética médica, que definiam prioridades detratamento e quais procedimentos deveriam ser utilizados.

H oje, a utilização de novas tecnologias e grande parte das pesquisas de novos procedimentos são avaliadas por comitês de ética em pesquisa, especialmente em centros universitários, garantindo uma prática mé

* Docente da Disciplina de Bioética, Faculdade de Medicina, Universidade de São Paulo (FM-USP), São Paulo, SP. Conselheiro, Conselho Regional de Medicina do Estado de São Paulo (CREMESP), São Paulo, SP.

J Vasc Br 2006;5(1):1-2.

Copyright $\odot 2006$ by Sociedade Brasileira de Angiologia e de Cirurgia Vascular. 
dica baseada em evidênciascientíficas eéticas. A despeito deste movimento que procura dar ao médico respaldo científico, tecnológico e ético para a sua ação, e ao doente a garantia e a segurança de uma boa prática médica, ainda existem indagações éticas e legais que fragilizam 0 ato, individual, do médico.

0 correqueo médico, em determinadascircunstâncias, deixa-se levar pelo "encanto" dos novos procedimentos e avanços tecnológicos, esquecendo-se de sua periculosidade (efeitosadversos); naverdade, esquecendo-se do necessário respaldo científico, técnico e ético para asua ação, quesignifica: ato médico. D iantedeum insucesso, a questão legal e ética transforma-se em um drama pessoal eprofissional de consequencias imprevisíveis.

As sociedades de especialidades freqüentemente agem demaneira correta ao possibilitar um processo de educação continuada, com atualização por meio da edição de revistas, promoção de seminários, congressos e, sobretudo, da elaboração dediretrizes parao diagnóstico e 0 tratamento de diferentes doenças. $N$ ormas indicativas e baseadas em evidências científicas procuram nortear a ação do médico na direção da boa prática.
M esmo assim, surgem dilemas quando da aplicação de uma ou outra técnica, do uso de um ou outro procedimento ou medicamento, cabendo, muitas vezes, ao médico, em particular, a difícil tarefa da opção. N este momento, a decisão deve estar respaldada na ética médica contida nos códigosnormativose no melhor da evidência científica.

Se entendermos que a participação do doente é importante, a discussão deve ser ampliada, e a decisão sobre a utilização do "novo e avançado" envolve mais pessoas: a família do doente. Esta estratégia de condução ética das questões rel acionadas com uma boa prática médica pode ser estimulada pelas sociedades de especialidades, promovendo o debate em suas publicações e em seus congressos sobre a autonomia do doente e a participação dos familiares nas decisões².

\section{R eferências}

1. Yoshida WB. Angiogênse, arteriogênese e vasculogênse: tratamento do futuro para isquemia crítica de membros? J V asc Br. 2005;4(4):316-8.

2. SegreM, C ohen C. Bioética. 3ạ ed. São Paulo: ED U SP; 2002.

\section{Colega Associado da SBACV}

Você está convidado a participar do crescimento e consolidação do J Vasc Br - como autor, leitor ou revisor.

Leia e divulgue; conheça as normas e submeta seus trabalhos.

\section{Jornal Vascular Brasileiro - Secretaria E ditorial}

Av. Protásio Alves, 1981 - sala 401

CEP 90410-002 - Porto Alegre, RS - Fone: (51) 3388.5000

E-mail: jvascbr@terra.com.br

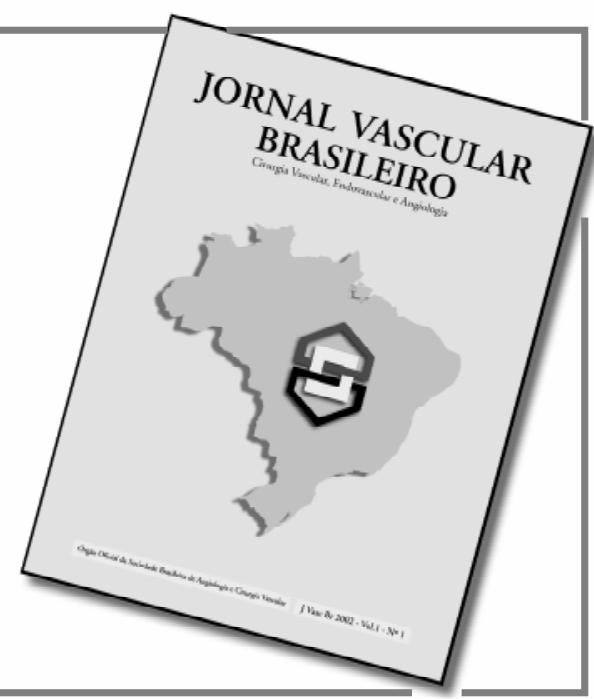

